\title{
Production potential of tidal flats for blood clam (Anadara granosa) culture in Bang-tabun bay, Phetchaburi province
}

\author{
Monissa Srisomwong ${ }^{\mathrm{a}}$, Shettapong Meksumpun ${ }^{\mathrm{a}, \mathrm{b}, *}$, Sansanee Wangvoralak ${ }^{\mathrm{c}}$, Nissara Thawonsode ${ }^{\mathrm{a}}$, \\ Charumas Meksumpun ${ }^{\mathrm{d}}$ \\ a Department of Marine Science, Faculty of Fisheries, Kasetsart University, Bangkok 10900 Thailand \\ b Centre for Advanced Studies in Tropical Natural Resources, \\ National Research University-Kasetsart University, Bangkok 10900 Thailand (CASTNAR, NRU-KU) \\ c Department of Fishery Management, Faculty of Fisheries, Kasetsart University, Bangkok 10900 Thailand \\ d Department of Fishery Biology, Faculty of Fisheries, Kasetsart University, Bangkok 10900 Thailand
}

*Corresponding author, e-mail: ffisspm@ku.ac.th

Received 5 Sep 2018

Accepted 28 Dec 2018

ABSTRACT: Production potential of blood clam (Anadara granosa) in Bang-tabun Bay was examined by integrating data for size distribution, growth rate, and aquatic environmental factors. Collection of data was conducted from December 2011 to May 2012. Blood clam culture areas from three muddy tidal flats; Don Bon flat, Don Klang flat, and Don Tuen flat located from the north to the south of the bay, respectively, were studied. Length and weight of clams at each station varied each month depending on the growth potential of the clam and culture management practices of farmers. The growth rate of blood clam throughout this study period ranged from $0.1-0.8 \mathrm{~g} / \mathrm{month}$. The results revealed significant correlations between blood clam growth rate, chlorophyll $a$ and salinity. Blood clam growth rate was most rapid at the station on Don Tuen flat, which exhibited the highest overall salinity and chlorophyll $a$. Don Klang flat and Don Bon flat can be adversely affected by freshwater runoff and food availability limiting the utility of these areas. Overall results indicate that among the three muddy tidal flats selected for this study, Don Tuen flat is the most suitable area for blood clam culture.

KEYWORDS: aquatic environment, growth rate, size distribution

\section{INTRODUCTION}

Blood cockles of the genus Anadara are muddy shore dwellers in intertidal or marginally subtidal areas, especially in shallow inlets or bays with a substratum of fine and soft mud. The preferred conditions for blood clam are large estuarine mudflats bordered on the landward margin by mangrove forests ${ }^{1-3}$. These clams provide food for coastal inhabitants and have economic importance in Thailand, Philippines, Malaysia, and Borneo ${ }^{2}$. Blood clam production in Thailand fluctuated from 1999-2010. Total annual production of the clam varied from 40979 ton/year to 81959 ton/year during that 12year period, with economic values ranging from $1038132000 \mathrm{THB} /$ year to $1725494000 \mathrm{THB} /$ year (31 834000-52906000 US\$) in the last 4 years (2007-2010) ${ }^{4}$. Blood clam production in Phetchaburi province, where the present study sites are lo- cated, fluctuated from $5313 \mathrm{t} /$ year to $22666 \mathrm{t} /$ year (113 501 000-498653000 THB/year or $3480000-$ 15292000 US\$). Blood clam production in Phetchaburi province was $13 \%$ of total Thailand production in 1999 and increased to $28 \%$ in 2009 , before decreasing to $13 \%$ in 2010 . The clam production in Phetchaburi province has influenced the total production of the country.

Bang-tabun bay in Phetchaburi province, located in the inner Gulf of Thailand and covered $12.98 \mathrm{~km}^{2}$ of the bay, is the second largest blood clam culture area in the nation. Bang-tabun bay has an abundance of bio-resources, and serves as a nursing ground for many aquatic organisms, especially the blood clam. The diversity of utilization patterns in the bay, fish capture and culture, affects water quality and composition of available food, and can impact the growth of blood clams. The growth rate of blood clams is also adversely affected by environmental conditions and population den- 
sity $^{1,3}$. Major environmental factors known to affect the growth of blood clams are substrate, salinity, dissolved oxygen, slope of the muddy flat where the clams are seeded, and availability of food ${ }^{1,5}$. Extreme variation in salinity, increased exposure period of the muddy flat, and the density of blood clams can limit the productivity and growth rates of mollusc species ${ }^{1,6}$.

The present study examined the production potential of clam culture in Bang-tabun Bay. All data for blood clam size distribution, seasonal variation in the culture area, related environmental factors, and food supply (in the form of chlorophyll $a$ ) were integrated. The goal of this study is to clarify the optimal area for blood clam culture in Bang-tabun Bay.

\section{MATERIALS AND METHODS}

\section{Study area}

The study area was located in Bang-tabun Bay, Phetchaburi province, in the inner Gulf of Thailand (Fig. 1). The bay is composed of three main muddy flats: Don Bon (local name of the muddy flat) in the north, Don Klang, and Don Tuen in the south (Fig. 1). Freshwater runoff is received from the Bang-tabun River. The water depth of the channel in the bay ranges from 1-8 $\mathrm{m}$ at flood tide (Fig. 2). The culture area was exposed to the air for $2-6 \mathrm{~h}$ during the ebb period in the spring tide.

\section{Water parameter collection}

The temperature, salinity, and dissolved oxygen (DO) of surface water were measured simultaneously using a multi-parameter probe (YSI-6600 Sonde instrument). Measurements were conducted in September and December 2011, and May 2012 at six stations (Fig. 1). At each station, samples of surface water (5 l) were collected and placed in polyethylene bags for analysis of chlorophyll $a$ and total suspended solids (TSS). Water samples were stored in the dark and cold environment immediately after collection.

\section{Blood clam sampling}

The sampling of clams was carried out at the same station and time as samples for water analysis, during the ebb period of neap tide. Blood clams were collected from a depth of approximately $10 \mathrm{~cm}$ of surface mud using a $15 \mathrm{~cm} \times 39 \mathrm{~cm}\left(10 \mathrm{~m}^{2} /\right.$ sample $)$ hand dredge with a square mesh containing $1 \mathrm{~cm}$ gaps. Clams were kept alive in plastic bags and transport to the laboratory. Shell length and body weight of the sampled clams were measured immediately after arrival at the laboratory.

\section{Sample analysis}

Chlorophyll a: An aliquot of $100-200 \mathrm{ml}$ of water sampled at each station was filtered through Whatman GF/F $\varnothing 25 \mathrm{~mm}$ membrane. The phytopigments from residue remaining on the filter were extracted by dipping the filters in $90 \%$ acetone for $24 \mathrm{~h}$ at $-20^{\circ} \mathrm{C}$. Chlorophyll $a$ concentration was determined by a spectrophotometric method ${ }^{7}$.

Total suspended solids (TSS): Known volumes of water samples (200-1000 ml) were filtered through pre-washed, -dried and -weighed Whatman GF/F $\varnothing 47 \mathrm{~mm}$. The filter papers were dried using the freeze drying technique. After drying, the filters were weighed again and the dry weights were recorded. TSS was then calculated using the U.S. Environmental Protection Agency (EPA) method $160.2^{8}$.

Blood clam analysis: Shell length $(\mathrm{cm})$ of the sampled clams was measured along the greatest antero-posterior direction using vernier calipers. The wet weight of clam ( $\mathrm{g}$ ) was measured using a 3-digit digital balance.

\section{Calculations}

Generally, shell length can be divided into plural normal distributions while this is not always the case for size distribution using body weight. In this study, cohorts of clams were influenced by seed manipulation and harvest activity. Cohort analysis of clams is better suited for analysis of shell length distribution, especially when growth rate needs to be discussed in body weight. Cohort analysis of blood clams was performed using Bhattacharya's method with the FISAT II program using the smallest mid-length and class interval of $2.5 \mathrm{~cm}$. In some stations, length distribution of clam consisted of more than one cohort, due to artificial manipulation giving rise to a polymodal distribution. Cohorts of each station were then carefully considered and selected for growth rate calculations according to their size improvement over time. Mean length of selected cohorts were computed and applied for average weight calculation using the formula $W=$ $a L^{\mathrm{b}}$, where $W$ is the total wet weight ( $\mathrm{g}$ ) and $L$ is the length $(\mathrm{cm})$, obtained from length-weight relationship analysis of 4141 pairs of clam length-weight measurement for all samplings. A comparison of each Anadara granosa cohort growth was carried out using the parameter weight. Growth rate $(G)$ of clam was calculated by $G=\left(W_{1}-W_{0}\right) / \Delta t$, where 


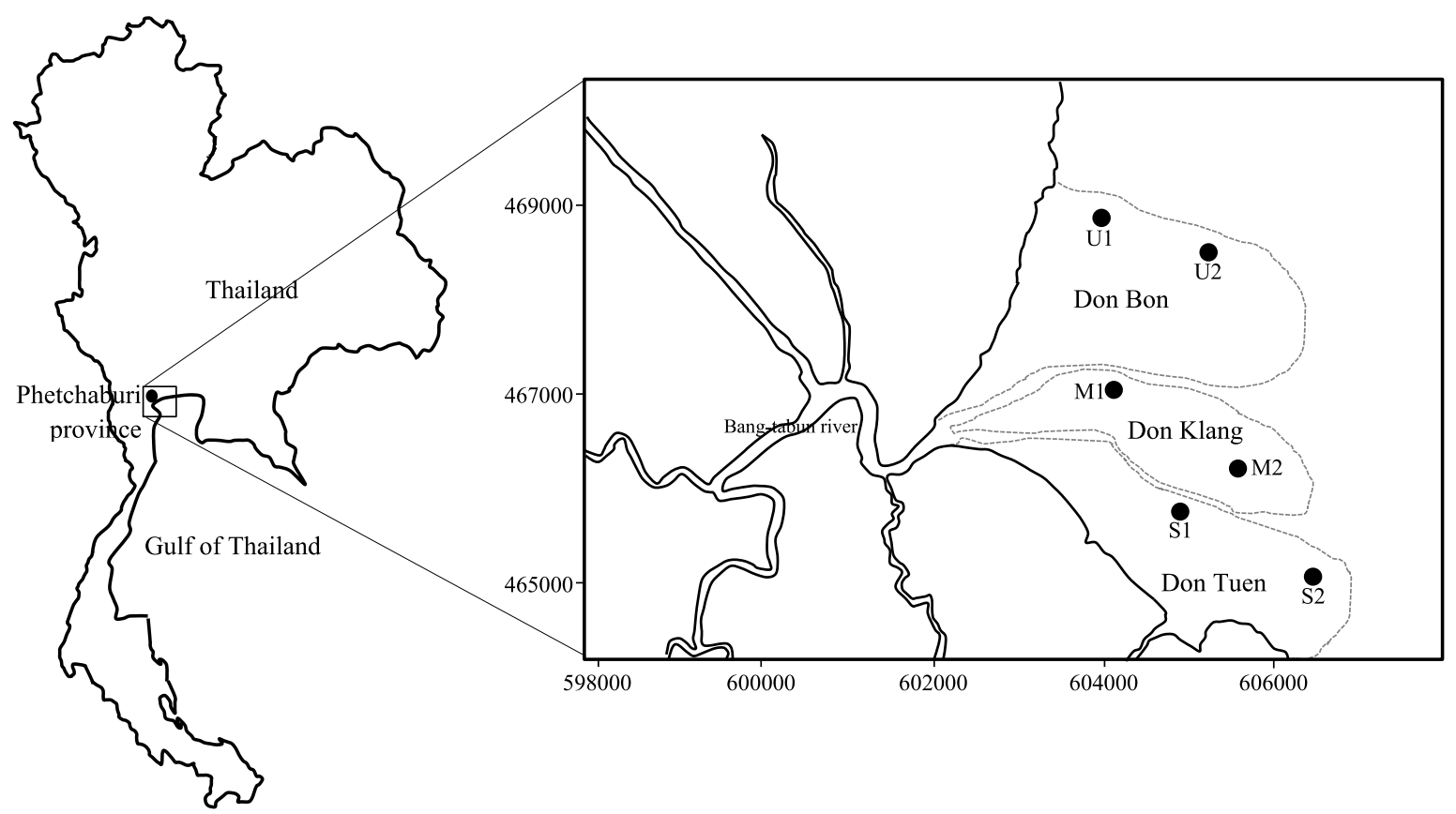

Fig. 1 Bang-tabun bay in Phetchaburi province is located in the inner Gulf of Thailand (left). The right panel shows the Bang-tabun river and Bang-tabun estuary. The mainland is shown with Bang-tabun river and its tributaries. The three main muddy flats; Don Bon, Don Klang, and Don Tuen are bounded by dashes. A total of six sampling stations are indicated. Stations U1 and U2 are on Don Bon flat, M1 and M2 are on Don Klang flat, and S1 and S2 are on Don Tuen flat.

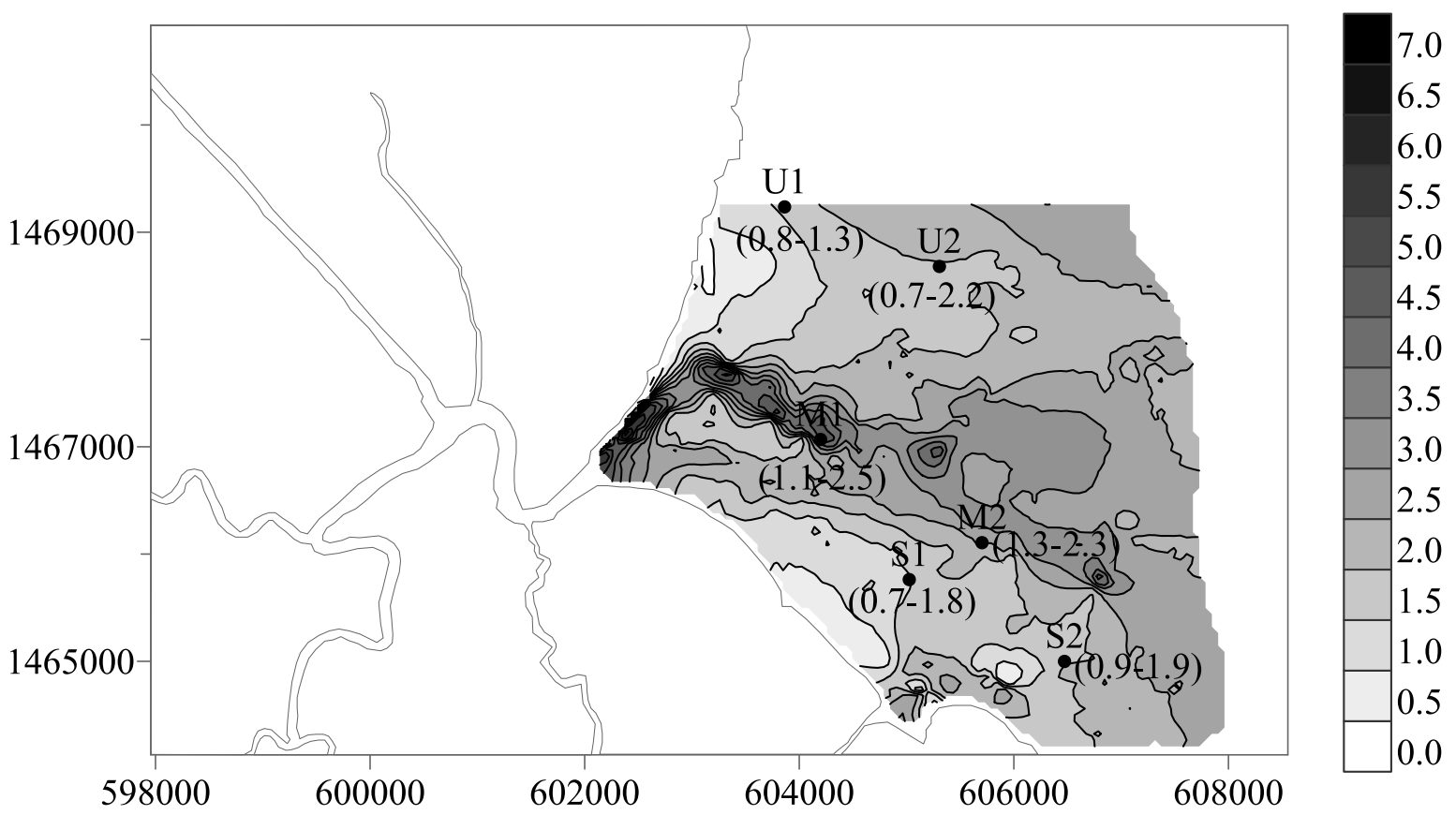

Fig. 2 Depth range and depth contour (m) of Bang-tabun bay at flood tide (August 2011). 
Table 1 Growth rate (g/month) of blood clam in sampled stations in Bang-tabun bay. G1, G2, and G3 show calculated growth rate, based on the weight differences between September and December 2011, December 2011 and March 2012, and March and May 2012, respectively.

\begin{tabular}{lcccc}
\hline Station & G1 & G2 & G3 & Average \\
\hline S1 & 0.90 & - & 0.32 & 0.61 \\
S2 & - & 0.70 & 0.90 & 0.80 \\
M1 & 0.66 & 0.20 & 0.17 & 0.34 \\
M2 & 0.58 & - & 0.90 & 0.74 \\
U1 & 0.13 & - & 0.07 & 0.10 \\
U2 & 0.37 & - & - & 0.37 \\
\hline
\end{tabular}

$W_{1}$ is the weight $(\mathrm{g})$ at a specified time, $W_{0}$ is the weight $(\mathrm{g})$ at time 0 , and $\Delta t$ is the time difference (months) of $t_{0}$ and $t_{1}$.

Average environmental factors were calculated using the recorded values from September, December, and May. In this study, production potential of blood clam was determined by the growth rate of the clam in each sampling site.

\section{Statistical analysis}

Environmental factor data were tested for normal distribution among groups using the KolmogorovSmirnov test. Regression analysis was used to examine the relationship between average growth rate of clams and environmental factors. Relationship analysis between average chlorophyll $a$ and TSS of the same site was also performed. The level for statistical significance was 0.05 .

\section{RESULTS}

\section{General water parameters}

The temperature, salinity, and DO in surface seawater, TSS, and chlorophyll $a$ in sampled seawater are given in Fig. 3. Temperature, salinity, and DO varied between sampled months. Salinity was less than $20 \%$ in September (5.4-14.8\%0) and December (14.8-18.6\%0), most probably due to the effect of freshwater runoff. Salinity increased in May (17.3-29.6\%0), which is the late dry season (March-May). Freshwater inflow and precipitationinduced drainage were factors affecting the salinity of water ${ }^{9}$. Chlorophyll $a$ and TSS fluctuated widely among stations and sampled months.

\section{Blood clam growth rate}

Blood clam length frequency for each cohort showed a normal curve distribution pattern in samples from all stations and all sampling times (Figs. 4 and 5).
At some sampling sites, more than one distribution curve was found for both small and large clams.

Length and weight analysis of blood clam indicated that the regression was highly significant with a coefficient of determination $\left(R^{2}\right)$ of 0.922 $(p<0.01)$. The length-weight relationship of blood clams was $W=0.379 L^{2.909}$ (Fig. 6).

Overall growth rate of blood clams (G1-G3) ranged from $0.07-0.90 \mathrm{~g} /$ month. The lowest growth rate was found at station U1 from Don Bon flat for G3. High growth rates were found at station M2 of Don Klang flat for G3 and station S1 and S2 of Don Tuen flat for G1 and G3, respectively. Disappearance of large clams in some stations was caused by harvest activity (Table 1). Station S2 was found to have the highest average growth rate $(0.80 \mathrm{~g} / \mathrm{month})$, followed by station M2 of Don Klang flat $(0.74 \mathrm{~g} /$ month $)$ and station S1 of Don Tuen flat $(0.61 \mathrm{~g} /$ month $)$, respectively.

\section{Relationship between growth rate and environmental factors}

Nonlinear regression analysis showed a significant relationship between annual growth rate with annual salinity and annual chlorophyll $a$. No significant relationship between annual TSS and growth rate was found. However, scatter plots suggest a trend of negative relationship between growth rate and TSS. Regression analysis between average chlorophyll $a$ and TSS indicated a significant negative relationship (Fig. 7).

\section{DISCUSSION}

The fluctuations of general water quality in the blood clam culture area in Bang-tabun Bay were similar to those in Ban Don Bay, Surathani province ${ }^{10}$, the largest clam culture area in Thailand, in Kakinada Bay, India ${ }^{11}$, and in Jeram, Malaysia $^{12}$. Water temperature, salinity, and DO observed in the study in Ban Don Bay ranged from $24.0-33.0^{\circ} \mathrm{C}, 6.0-32.0 \%$, and $4.0-8.5 \mathrm{mgO}_{2} / 1$, respectively. The parameters in Kakinada Bay ranged from $28.0-33.5^{\circ} \mathrm{C}, 15.1-34.4 \%$, and $5.2-$ $6.8 \mathrm{mgO}_{2} / \mathrm{l}$, respectively, and in Jeram ranged from $29.5-32.5^{\circ} \mathrm{C}, 13.9-31.2 \%$, and $2.3-8.5 \mathrm{mgO}_{2} / \mathrm{l}$, respectively. Observed water temperature, salinity, and DO in Bang-tabun Bay were within the range for the standard level of water quality suitable for aquaculture in Thailand, as stipulated by the Pollution Control Department of Thailand (infofile. pcd.go.th/law/134_288.pdf, in Thai). Ref. 10 also found more than one normal curve size distribution of blood clams in culture areas in Suratthani 

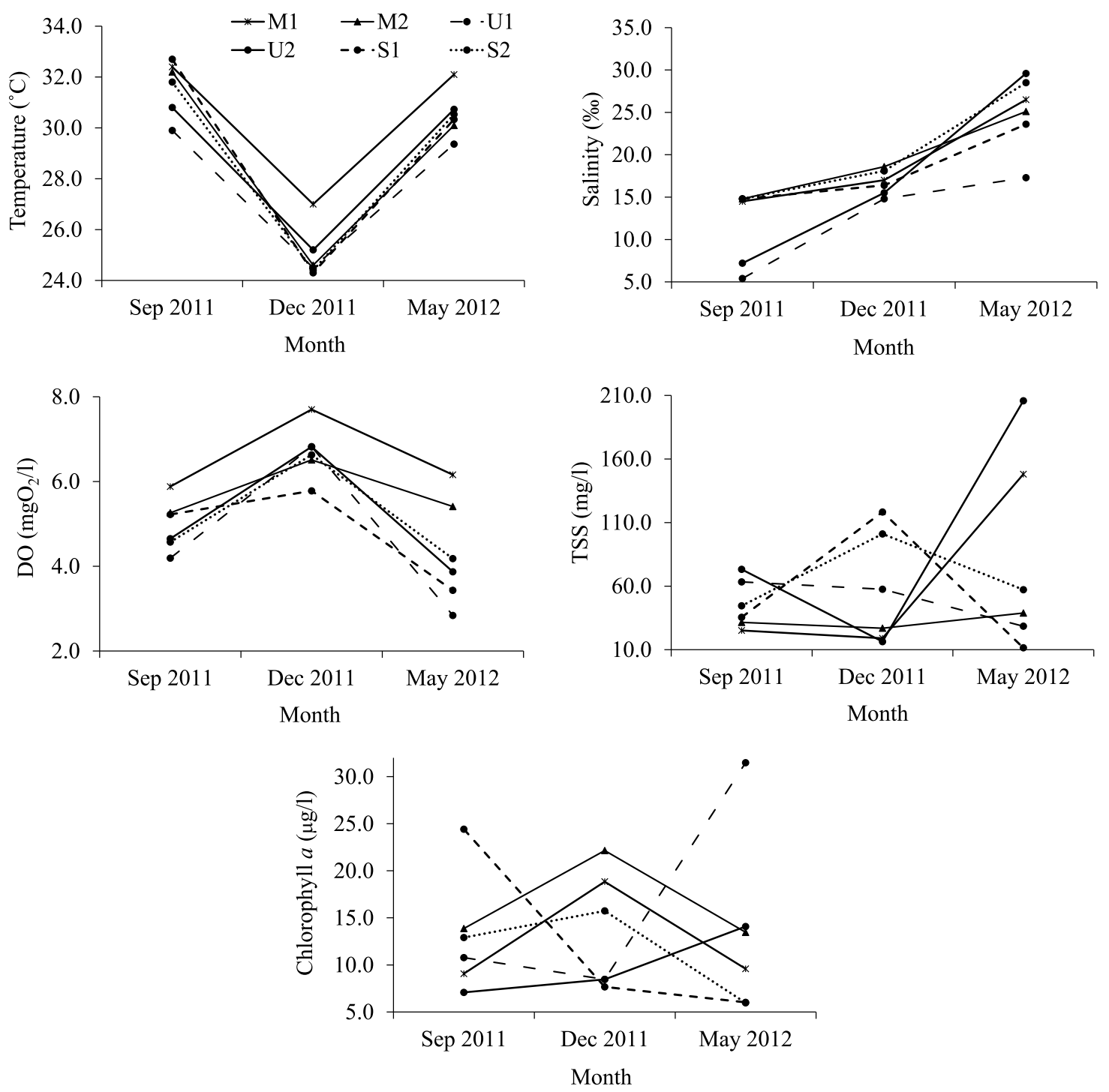

Fig. 3 Water quality at the stations in Bang-tabun bay in September and December 2011 and May 2012.

province, Thailand, which was attributed to the irregular growth of clams. The maximum growth rate found in the present study $(0.80 \mathrm{~g} / \mathrm{month})$ was close to the growth rate of blood clams in Phangnga Bay, Phang-nga province but was less than that observed at Pattani Bay, Pattani province and Ban Don Bay, Suratthani province. Blood clams at Phang-nga Bay were reported to have growth rates of $0.89 \mathrm{~g} /$ month $^{13}$. The growth rate of clams in Pattani Bay was up to $1.55 \mathrm{~g} /$ month $^{14}$ and ranged from 1.01-1.36 g/month in Ban Don Bay ${ }^{10}$.

Salinity in Bang-tabun Bay ranged from 5.429.6\% (Fig. 3). Lower salinity was found in Don Bon flat (U1, U2) followed by Don Klang flat
(M1, M2) and Don Tuen flat (S1, S2), respectively. Scatter plot of average growth rate and salinity showed that the growth rate of blood clams tended to reduce at stations where the salinity was low (Fig. 7a). Freshwater inflow and precipitationinduced drainage were factors affecting salinity of the water in the study area ${ }^{9}$, especially stations M1, $\mathrm{U} 1$, and U2. Blood clams can normally survive in low salinity conditions for only a few days. Longer exposure to low salinity can result in mortality ${ }^{1}$. Stations U1 and U2 were located on the upper flat with the greatest freshwater runoff effect from the Maeklong River, located beyond the north part of the bay. Stations in the upper flat receive freshwater 

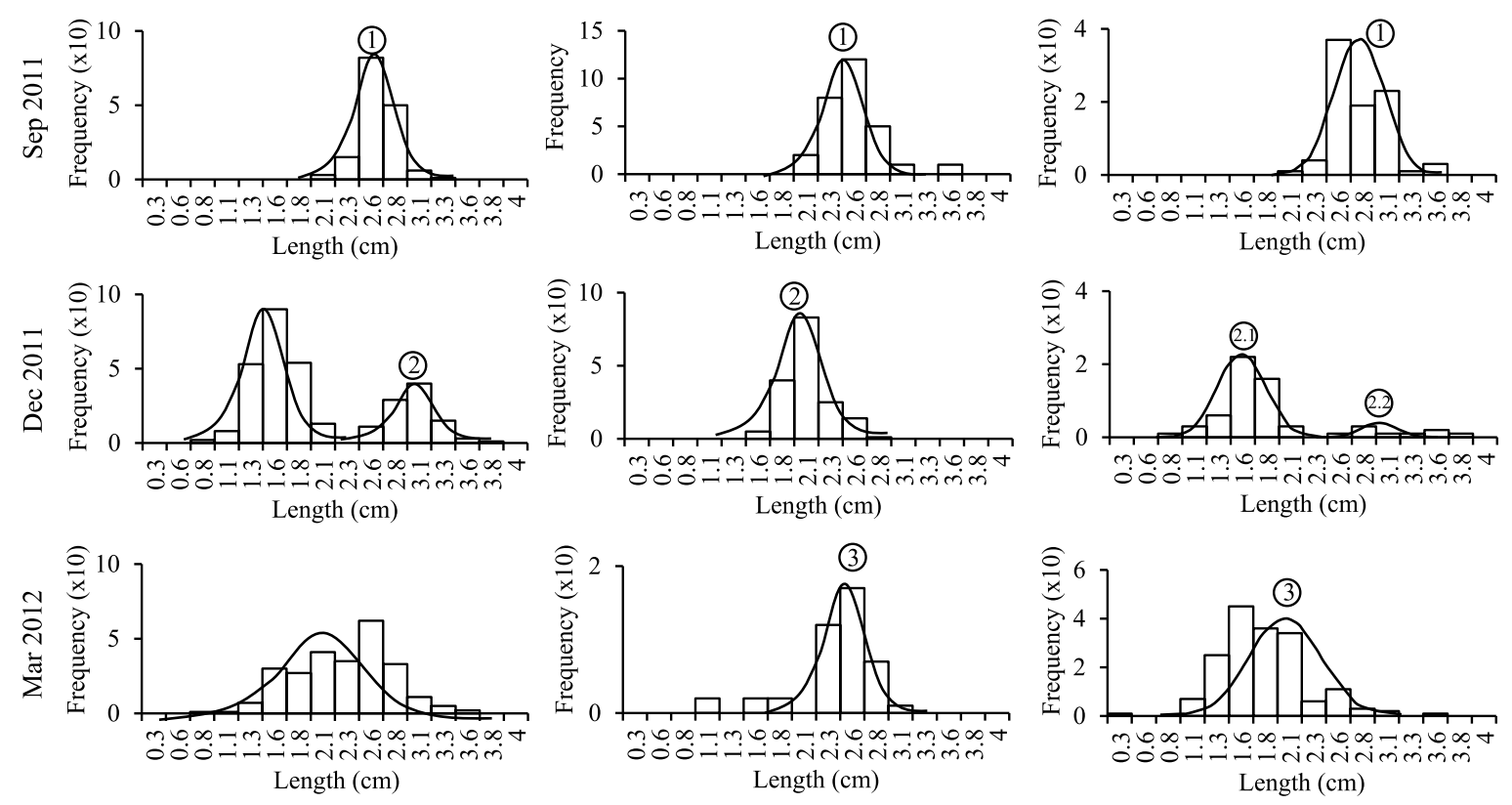

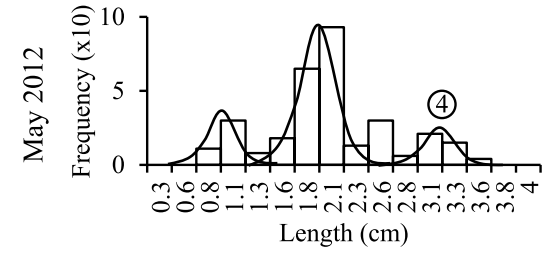

S1

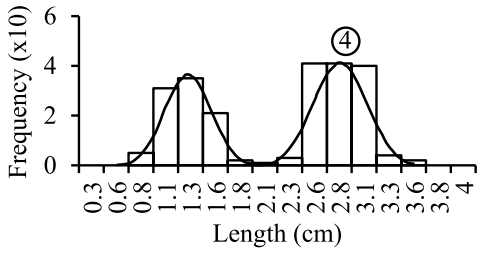

S2

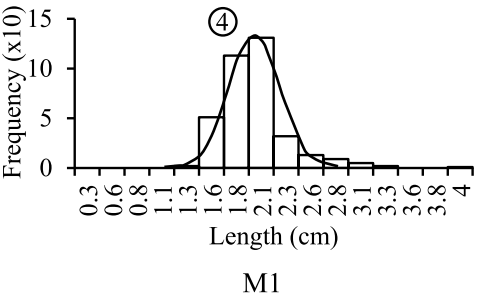

Fig. 4 Length frequency of blood clams from station S1, S2, and M1. Numbers indicate cohort used for growth calculation. At S1, average weights of no. 1 and 2 were used to calculate G1 while no. 2 and 4 were used to calculate G3. At S2, average weights of no. 2 and 3 were used to calculate G2 while no. 3 and 4 were used to calculate G3 and large blood clam was harvested between September 2011 and December 2011. At M1, average weights of no. 1 and 2.2 were used to calculate G1 while no. 2.1 and 3 were used to calculate G2.

runoff, where reduced salinity may have adversely affected the growth of clams. This finding coincides with the study by Silina ${ }^{15}$, which revealed that the growth rate of the blood clam A. broughtonii is slower at sites close to a river mouth. Station M1 was located at the river mouth where blood clams directly encountered freshwater runoff from the Bang-tabun River. Blood clams tightly close their shell when salinity falls from 32 to $16 \%$, and shells remain closed at salinity below $16 \%{ }^{16}$. This prevents clams from feeding during conditions of low salinity. In salinity of 28 to $11 \%$, Anadara sp. feed only sporadically and no feeding activities were detected at salinity of $6 \%{ }^{17}$. Broom ${ }^{1}$ also mentioned that salinity above $23 \%$ would allow Anadara sp. to feed relatively efficiently while salinity less than $20 \%$ o would result in decreased feeding efficiency and activity. In this study, blood clam of stations U1 and U2 experienced salinity of 5.4\%o and $7.2 \%$, respectively, the condition which could have a negative effect on growth rate.

Air exposure can also affect the growth of blood cockles $^{18}$. Fig. 2 shows that the topography of Don Bon flat resulted in longer exposure to the air at station U1 and U2 during ebb tide than the other sampling sites. Organisms in such places would have limited time to feed and thus would suffer from a restriction in food supply ${ }^{18}$. Extended air exposure, in addition to the low salinity, may have reduced the clam growth rate in U1 and U2. Ref. 16 also reported that blood clams die quickly without sufficient moisture.

The chlorophyll $a$ content of water was positively correlated with growth rate $\left(r_{\mathrm{s}}=0.846\right)$. High growth rates of blood clam was observed in the areas of greatest concentration of chlorophyll $a$. This was in agreement with the research on the effect of environmental factors on condition index of 

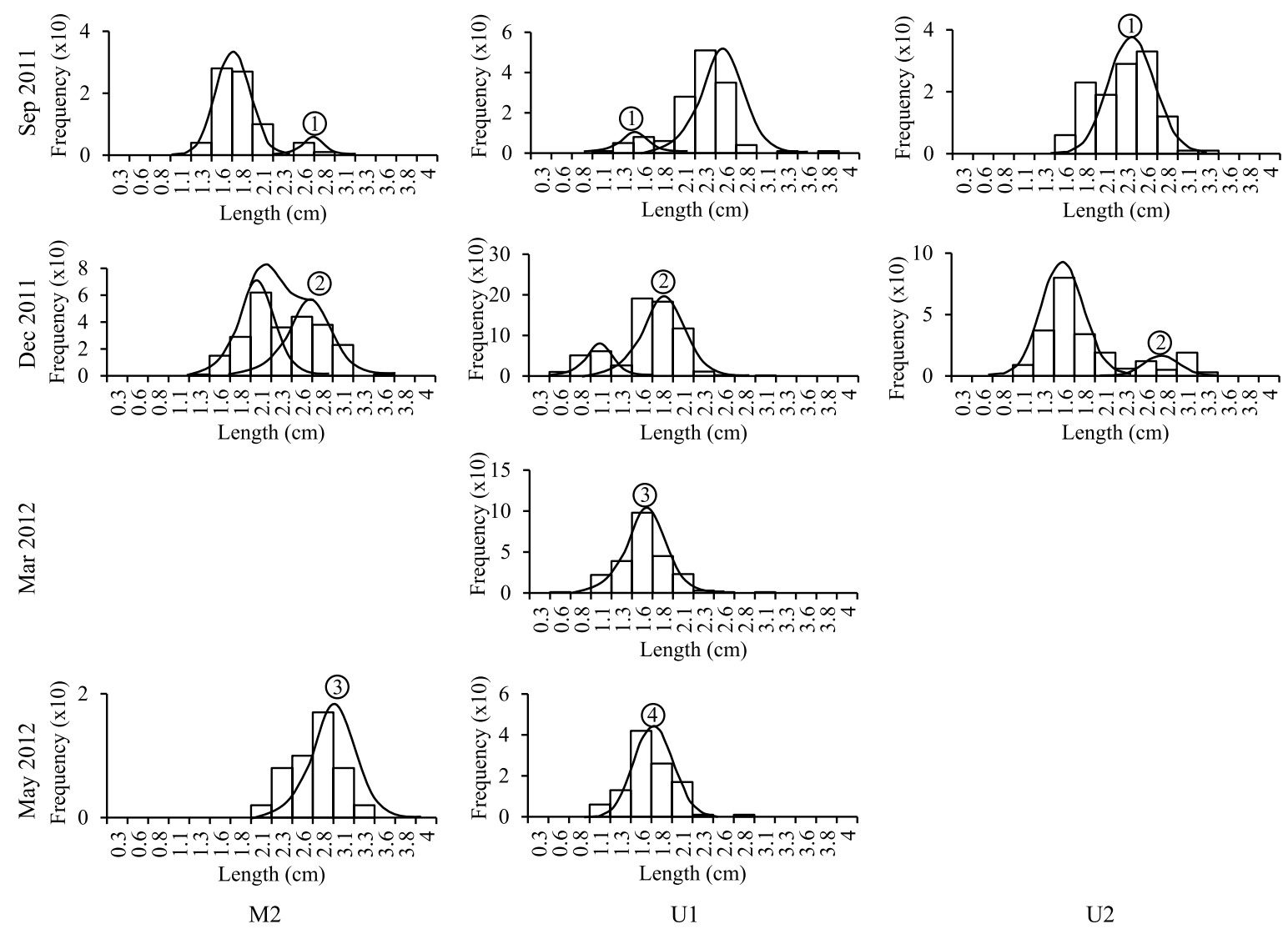

$\mathrm{U} 2$

Fig. 5 Length frequency of blood clams from station M2, U1, and U2. Numbers indicate cohort used for growth calculation. At M2, average weights of no. 1 and 2 were used to calculate G1 while no. 2 and 3 were used to calculate G3. At U1, average weights of no. 1 and 2 were used to calculate G1 while no. 3 and 4 were used to calculate G3. At U2, average weights of no. 1 and 2 were used to calculate G1.

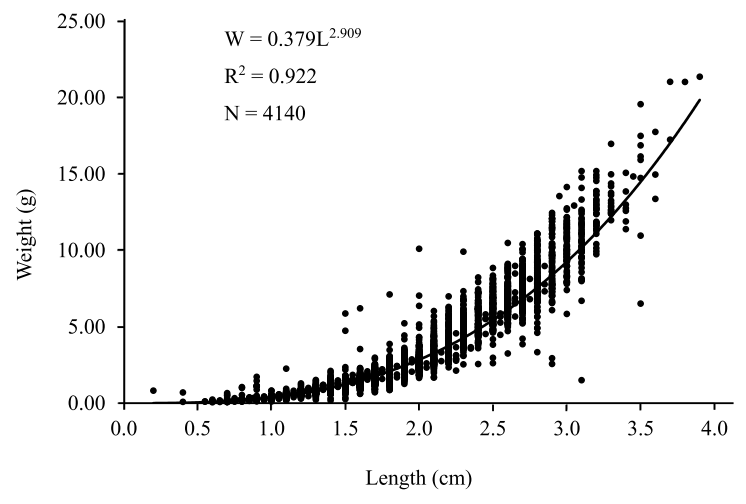

Fig. 6 The length-weight relationship for blood clam Anadara granosa ( $N$ : number of samples; $R^{2}$ : coefficient of determination).

blood cockles in Bandon Bay ${ }^{19}$ and the relationship of Mytilus edulis growth on water temperature and food availability in the US waters ${ }^{20}$. In nature, growth of mollusc is known to be supported by food availability, i.e., phytoplankton abundance ${ }^{5}$, which in this case is represented by chlorophyll $a$ concentrations. Apart from phytoplankton, other organic particles were also found to be food sources of most clams $^{21}$. In the muddy habitat where sediment is easily resuspended, benthic microalgae and a mixture of detritus or microorganisms attached to detritus could serve as food sources for blood clam ${ }^{1,5}$. In contrast to chlorophyll a concentrations, a negative trend was found between TSS and growth rate of blood clam. This could be explained by the negative correlation between TSS and chlorophyll $a$. Stations with high TSS were observed to exhibit low concentrations of chlorophyll $a$, except station U2. This indicates that TSS might be composed of inorganic particles which cannot be utilized by blood clam as food and consequentially result in low growth rate. For station U2, where high TSS and high chlorophyll $a$ concentration were found 

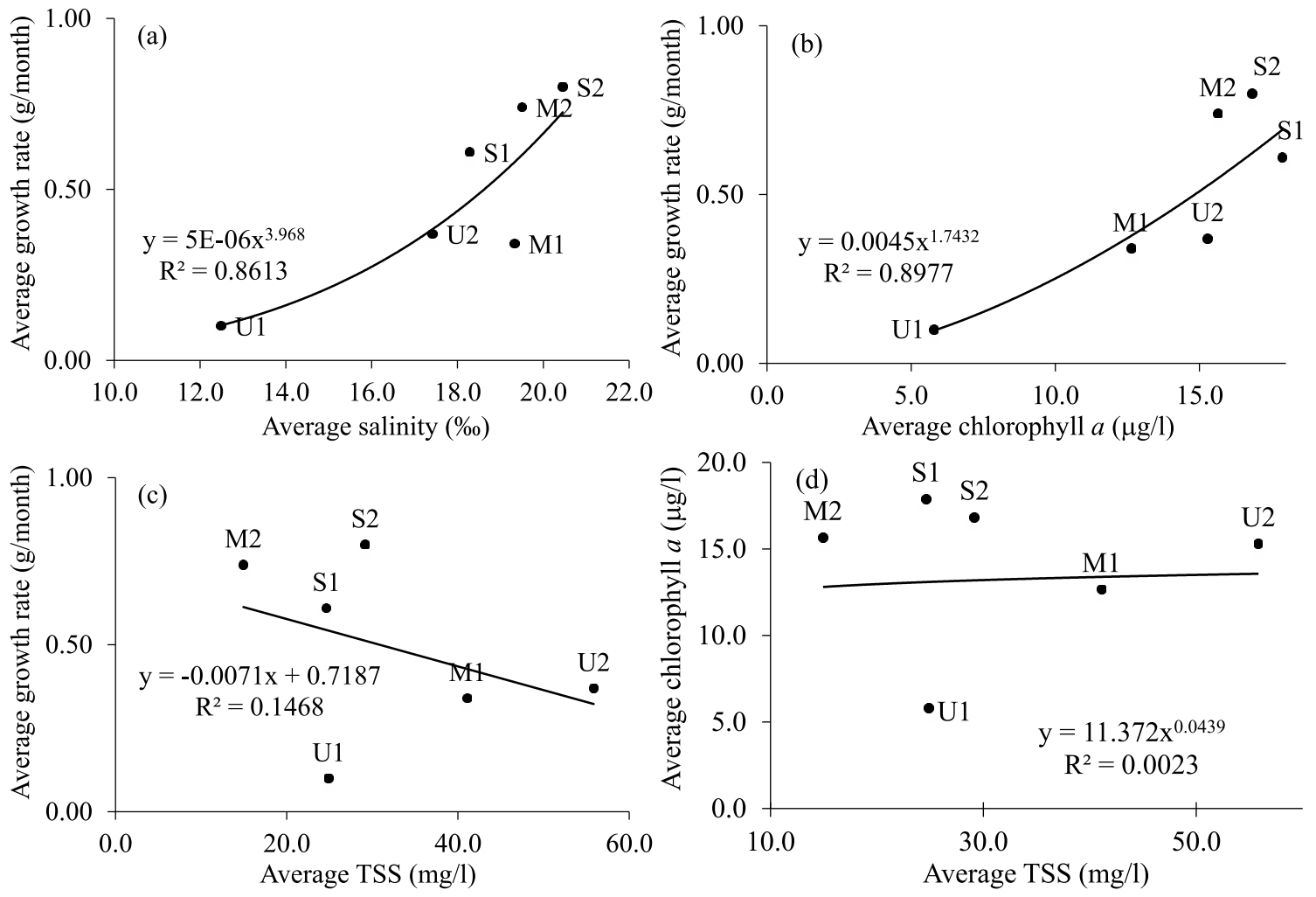

Fig. 7 Relationship between the environmental factors and average growth rate of the blood clam (a-c), TSS and chlorophyll $a$ in sampled sea water $(\mathrm{d})$.

together, a low growth rate was also observed. It is possible that the phytoplankton was not fully consumed by blood clam due to obstacles to filter feeding. Bivalve molluscs are not good at filtering water with high concentration of suspended solid ${ }^{1}$, thus making them unable to perform proper feeding. Appropriate concentrations of suspended solid could enhance growth of the bivalves ${ }^{5}$.

High salinity, high chlorophyll $a$ concentration, and low TSS was found to promote high growth rate of blood clam in the station of $\mathrm{M} 2, \mathrm{~S} 1$, and S2. This suggests that these stations are located at a suitable mixing area of seawater and freshwater for the blood clam and this environment is also suitable to produce abundant phytoplankton. Phytoplankton is known to require sources of nitrogen and phosphorous for proper growth ${ }^{22}$. The stations of M2, S1, and S2 had higher concentrations of ammonium-nitrogen and orthophosphatephosphorous than other stations in this survey. Furthermore, aquatic environments could be roughly classified into 2 areas as 'low productive' and 'high productive' based on salinity, chlorophyll $a$, and TSS. Low productive areas in the stations M1, U1, and U2 presented low growth rates for blood clam due to low salinity, low chlorophyll a concentration, and high TSS. On the other hand, the high productive areas of the stations M2, S1, and S2, exhibiting high salinity, high chlorophyll $a$ concentration and low TSS, produced high growth rates for clam. From the overall results, a suitable environment for the blood clam culture could be determined to contain salinity around $20 \%$, chlorophyll a concentration around $15 \mu \mathrm{g} / \mathrm{l}$, and TSS less than $30 \mathrm{mg} / \mathrm{l}$ in Bangtabun bay.

\section{CONCLUSIONS}

Average growth rate of clams in stations closed to the river mouth were lower than the outer stations of the same flat. Overall results revealed that the highest average growth rate of clams, a measure of the potential for the area, was found in Don Tuen flat. In addition, stations S1 and S2 at Don Tuen flat showed the highest production potential of the six stations in terms of growth rate for blood clam culture in Bang-tabun Bay. In relation to the environmental conditions of the areas, S1 and S2 gave the highest growth rates followed by station 
M2 on Don Klang flat, and station U2 on Don Bon flat, respectively. These findings indicate that environmental factors have substantial influenced on the growth of the clam. Suitable environments for blood clam culture in Bang-tabun bay were established at the salinity around $20 \%$, chlorophyll $a$ concentration around $15 \mu \mathrm{g} / \mathrm{l}$, and TSS less than $30 \mathrm{mg} / \mathrm{l}$. An optimum environmental condition and the production potential of the region should be taken into consideration when arranging the areas for blood clam culture or managing culture activities to assist farmers to obtain sustainable utilization of the region.

Acknowledgements: We are grateful to all members of Aquatic Environment Laboratory of Marine Science Department and Sediment Laboratory of Fishery Biology Department, Faculty of Fisheries, Kasetsart University for their assistance in fieldwork and support. We also wish to thank Assoc. Prof. Jirarpast Adjimangkunl for helpful comments. This work was supported by the Higher Education Research Promotion and National Research University Project of Thailand, Office of the Higher Education Commission.

\section{REFERENCES}

1. Broom MJ (1985) The biology and culture of marine bivalve molluscs of the genus Anadara. ICLARM Stud Rev 12, 1-37.

2. Pathansali D, Soong MK (1958) Some aspects of cockle (Anadara granosa L.) culture in Malaya. In: Proceedings of the Indo-Pacific Fisheries Council 8, pp 26-31.

3. Tiensongrusmee B, Pontjoprawiro S (1988) Cockle Culture, INS/81/008 Manual, 12.

4. Department of Fisheries (2016) Statistic of Marine Shellfish Culture Survey 2016, Department of Fisheries, Thailand.

5. Gosling E (2003) Bivalve Molluscs Biology, Ecology and Culture, Blackwell Publishing, Oxford, UK.

6. Pathansali D (1966) Notes on the biological of the cockle Anadara granosa L. Proc Fish Counc 11, 84-98.

7. Parsons TR, Maita Y, Lalli CM (1984) A Manual of Chemical and Biological Methods for Seawater Analysis, Pergamon Press, Oxford, UK.

8. NCASI (1977) A Study of the Effect of Alternate Procedures on Effluent Suspended Solids Measurement, Technical Bulletin 291, NCASI.

9. Thongdonphum B, Meksumpun S, Meksumpun C (2011) Nutrient loads and their impacts on chlorophyll $a$ in the Mae Klong River and estuarine ecosystem: an approach for nutrient criteria development. Water Sci Technol 64, 178-88.

10. Vichaiwattana C, Thepphanich A (2008) Some biological aspects, water-sediment qualities and cost- benefit of the culture of Anadara nodifera (Martans, 1860) and Anadara granosa (Linnaeus, 1758) in Ban Don Bay, Suratthani Province. Technical Paper 42/2008, Fishery Department, Thailand.

11. Narasimham KA (1987) Aspects of the blood clam, Anadara granosa (LINNAEUS) culture in Kakinda Bay. CMFRI Bulletin 42, 313-7.

12. Pahri SDR, Mohamed AF, Samat A (2016) Preliminary water quality study in cockle farming area in Malaysia: a case study in Jeram, Selangor. AACL Bioflux 9, 316-25.

13. Senagulp A, Pariyawati S (1985) Production assessment of blood cockle in Phang-Nga Bay 1983-1984. Fish Bull 38, 115-21.

14. Tookwinas S, Peangmark P, Sirimontaporn P, Tuaycharoen S, Sangsakul P (1987) Study on the growth rate of blood cockle, Anadara granosa L., and aquatic environment at culture bed in Pattani Bay. In: Proceedings of the 25th Kasetsart University Annual Conference, Bangkok, pp 222-34.

15. Silina AV (2006) Spatial heterogeneity and long-term changes in bivalve Anadara broughtonipopulation: influence of river runoff and fishery. Ocean Sci 41, 211-9.

16. Davenport J, Wong TM (1986) Response of the blood cockle Anadara granosa (L.) (Bivalve: Arcidae) to salinity, hypoxia and aerial exposure. Aquaculture 56, 151-62.

17. Nakamura Y, Shinotsuka Y (2007) Suspension feeding and growth of ask shell Anadara granosa: comparison with ubiquitous species Scapharca subcrenata. Fish Sci 73, 889-96.

18. Broom MJ (1982) Analysis of the growth of Anadara granosa (Bivalve: Arcidae) in natural, artificially seeded and experimental populations. Mar Ecol Prog Ser 9, 69-79.

19. Jarernpornnipat A, Buppha N (2012) Effect of environmental factors on condition index of blood cockle (Anadara spp.) in Bandon Bay, Suratthani-Thailand. In: Proceeding of International Fishery Symposium 2012, Can Tho, Viet Nam, pp 22-8.

20. Page HM, Hubbard DM (1987) Temporal and spatial patterns of growth in mussel Mytilus edulis on an offshore platform: relationships to water temperature and food availability. J Exp Mar Biol Ecol 111, 159-79.

21. Meshram AM (2015) Biological studies of blood clam, Tegillarca (Anadara) rhombea (Born, 1778) along Ratnagiri coast, Maharashtra. MSc thesis, College of Fisheries, Ratnagiri.

22. Dawes CJ (1981) Marine Botany, A WileyInterscience Publication, USA. 